\title{
ENRAIZAMENTO EX VITRO E ACLIMATIZAÇÃO DO PORTA-ENXERTO DE MACIEIRA M.9 ${ }^{1}$
}

\author{
ENIO LUIZ PEDROTTI ${ }^{2}$, JOSÉ AFONSO VOLTOLINI ${ }^{3}$
}

\begin{abstract}
RESUMO - A micropropagação pode ser utilizada para a produção deste porta-enxerto; no entanto, o enraizamento e a aclimatização são pontos de estrangulamento para o uso comercial desta tecnologia. O presente trabalho foi conduzido com o objetivo de avaliar diferentes níveis de ácido indolbutírico (AIB) no enraizamento ex vitro e aclimatização simultânea do porta-enxerto de macieira 'M.9'. As bases das miniestacas oriundas do processo de multiplicação in vitro, com 2,5 a $3 \mathrm{~cm}$ de altura e dois pares de folhas, foram imersas em AIB nas concentrações de 0; 500; 1000 e $1500 \mathrm{mg} . \mathrm{L}^{-1}$, por 10 segundos. Após, foram transferidas para bandejas de isopor com células contendo $50 \mathrm{~mL}$ do substrato casca de arroz carbonizada + vermiculita $(1: 1, \mathrm{v} / \mathrm{v})$. As bandejas foram mantidas durante 30 dias em caixas plásticas cobertas com tampas de vidro para manter o ambiente com alta umidade. Os melhores resultados para a percentagem de enraizamento ( 82 e $84 \%$ ) foram obtidos nos tratamentos com 500 e $1000 \mathrm{mg}$.L-1, respectivamente. O comprimento das raízes não foi afetado pelos tratamentos aplicados, apresentando média de 4,2 cm. As concentrações maiores de AIB determinaram acréscimos lineares no número de raízes emitidas. Para avaliar a aclimatização, as plantas foram transferidas para casa de vegetação, em bandejas de isopor com alvéolos maiores, contendo o substrato Plantmax ${ }^{\circledR}$ (Eucatex, São Paulo, BR) durante 45 dias. Os maiores índices de sobrevivência das mudas após o transplante para embalagens comerciais (95\%) foram obtidos com $500 \mathrm{mg} . \mathrm{L}^{-1}$ de AIB; no entanto, as concentrações de AIB empregadas na indução à rizogênese não modificaram o número e comprimento das raízes, número de folhas e altura das plantas.
\end{abstract}

Termos para Indexação: Malus pumila, micropropagação, substrato, ácido indolbutírico

\section{EX VITRO ROOTING AND ACCLIMATIZATION OF M.9 APPLE ROOTSTOCK}

\begin{abstract}
The M.9 rootstock is utilized in high-density apple orchards due to the low height of the plants, which facilitates care during cultivation and picking. Micropropagation can be utilized for its mass propagation, although rooting and acclimatization are impediments for the commercial use of this technology. This study was conducted in order to evaluate different levels of indolebutyric acid (IBA) in ex vitro rooting and simultaneous acclimatization of M.9 apple rootstock. The bases of the shoots resulting from the in vitro multiplication process, 2.5 to $3 \mathrm{~cm}$ in height and with two pairs of leaves, were immersed in concentrations of IBA of 0; 500; 1000 and $1500 \mathrm{mg} \cdot \mathrm{L}^{-1}$, for 10 seconds and placed in Styrofoam trays with cells containing $50 \mathrm{ml}$ of substrate containing carbonized rice husks + vermiculite $(1: 1, \mathrm{v} / \mathrm{v})$. For 30 days the trays were kept in plastic boxes covered with glass tops to keep the environmental humidity high. The higher percentages of rooting ( 82 and $84 \%$ ) were obtained in the treatments with 500 and $1000 \mathrm{mg} . \mathrm{L}^{-1}$, respectively The length of the roots, with an average of $4.2 \mathrm{~cm}$, was not affected by the treatments applied. After this evaluation, the plants were cultivated in a greenhouse for 45 days, in containers with the substrate Plantmax ${ }^{\circledR}$ (Eucatex, São Paulo, BR). The levels of IBA utilized in the rhyzogenesis induction did not modify the number and the length of the roots or the number of leaves and the height of the plants although the highest survival of the plantlets after transplant to commercial packages (95\%) was obtained with $500 \mathrm{mg}$. $\mathrm{L}^{-1} \mathrm{of}$ IBA.
\end{abstract}

Index terms: Malus pumilla, micropropagation, substrate, indolbutiric-acid

\section{INTRODUÇÃO}

O Estado de Santa Catarina produziu 480 mil toneladas de maçãs na safra $99 / 00$, totalizando $60 \%$ da produção nacional (ICEPA, 2000). Os tratos culturais, o sistema de condução e a alta qualidade genética e fitossanitária das mudas utilizadas são fatores determinantes para o aumento da produtividade. Neste contexto, a alta densidade de plantio dos pomares exige portaenxertos ananizantes e, conseqüentemente, grande quantidade de mudas por unidade de área. O porta-enxerto M.9 é o mais utilizados no Estado em pomares de alta densidade devido ao porte reduzido das plantas, o que facilita o manejo dos pomares.
A micropropagação de macieira é uma técnica empregada para a obtenção e produção massal de plantas livres de vírus. Entretanto, um dos pontos limitantes desta técnica são o enraizamento e a aclimatização das plantas micropropagadas (Sutter, 1988). Para Collet \& Lê (1987) e Àlvarez et al. (1989), a propagação clonal in vitro de espécies lenhosas é dificultada principalmente porque muitas delas não produzem raízes. $\mathrm{O}$ genótipo da planta determina diferentes respostas nos diferentes estágios da micropropagação (Harbage e Stimart, 1996) e/ou no enraizamento (Marks, 1991; Haissig et al., 1992). Essas respostas dependem da condição fisiológica dos explantes e das condições ambientais utilizadas. 
O enraizamento é uma etapa realizada classicamente in vitro (Álvares et al., 1989; Harbage \& Stimart, 1996; De Klerk et al., 1997), aumentando, contudo, os custos de produção (Ferri et al., 1998). Além disto, as raízes produzidas in vitro não sobrevivem após a transferência das plantas para o estágio de aclimatização (McClelland et al.,1990). Para a maioria das espécies, ao enraizamento, é necessária a presença de uma auxina no meio de cultura, na fase de indução (De Klerk et al., 1995). A quantidade a ser adicionada no meio de cultura depende das concentrações endógenas de auxinas do explante utilizado (James e Thurnbon, 1981; Blakesley et al., 1991).

Já o enraizamento ex vitro reduz o custo de produção das mudas (Debergh e Maene, 1981), podendo viabilizar, técnica e economicamente, o processo de micropropagação.

Para a sobrevivência das mudas no estágio de aclimatização, é necessário que estas produzam novas raízes em substratos porosos, com condições físicas e nutricionais adequadas. Simultaneamente, a planta deverá desenvolver mecanismos de controle de transpiração e condutância estomática (Díaz-Perez et al., 1995), ativar os mecanismos de controle de perda de água pelas células (Sutter, 1988) e aumentar a taxa fotossintética em condições de atmosfera mais rica em $\mathrm{CO}_{2}$ (Vantelgen et al., 1992). A baixa luminosidade e alta umidade relativa nos frascos de cultura in vitro dificultam o estabelecimento de condições autotróficas normais para algumas espécies, quando transferidas para as condições ex vitro.

$\mathrm{O}$ objetivo deste trabalho foi quantificar as respostas ao enraizamento e a aclimatização de miniestacas do portaenxerto de macieira M.9, em diferentes concentrações de ácido indolbutírico.

\section{MATERIAL E MÉTODOS}

\section{Cultivo in vitro}

Os meristemas foram retirados de plantas matrizes do porta-enxerto M.9 mantidas em casa de vegetação. Os meristemas foram introduzidos em meio MS (Murashige \& Skoog, 1962), e as brotações produzidas foram repicadas para o meio MS com $1,1 \mu \mathrm{M}$ de 6-benzilaminopurina (6-BAP), $100 \mathrm{mg} . \mathrm{L}^{-1}$ de mioinositol, 30g. $\mathrm{L}^{-1}$ de sacarose e $6 \mathrm{~g} . \mathrm{L}^{-1}$ de ágar. Para o estágio de micropropagação, foram empregados $50 \mathrm{~mL}$ de meio de cultura em frascos com capacidade de $300 \mathrm{~mL}$, autoclavados durante 20 minutos a $121^{\circ} \mathrm{C}$. Os frascos foram mantidos em câmara de crescimento com temperatura de $27 \pm 2^{\circ} \mathrm{C}$, fotoperíodo de 16 horas com intensidade luminosa de $50 \mu \mathrm{mol} \cdot \mathrm{m}^{-2} \cdot \mathrm{s}^{-1}$.

\section{Enraizamento e aclimatização}

As miniestacas de 2,5 a $3 \mathrm{~cm}$ de comprimento, com dois pares de folhas, foram preparadas a partir de plantas micropropagadas repicadas in vitro a cada 45 dias. A indução ao enraizamento foi efetuada submergindo $10 \mathrm{~mm}$ da base das miniestacas durante 10 segundos, em diferentes concentrações de ácido indolbutírico $\left(0 ; 500 ; 1000\right.$ ou $\left.1500 \mathrm{mg} . \mathrm{L}^{-1}\right)$. Em seguida, as miniestacas foram transferidas para bandejas de isopor com células com capacidade de $50 \mathrm{~mL}$ do substrato, composto por casca de arroz carbonizada e vermiculita média 1:1 (v/v.). As bandejas foram colocadas dentro de caixas plásticas com uma lâmina de água de $5 \mathrm{~mm}$, para manter elevada a umidade relativa do ar. As caixas foram cobertas com uma lâmina de vidro, conforme metodologia descrita por Pedrotti (1993). Durante 30 dias, essas caixas foram mantidas em câmara de aclimatização com temperatura de $27 \pm 2{ }^{\circ} \mathrm{C}$, fotoperíodo de 16 horas e intensidade luminosa de $75 \mu \mathrm{mol} \cdot \mathrm{m}^{-2} \cdot \mathrm{s}^{-1}$. Após esse período, as plantas foram avaliadas quanto ao percentual de enraizamento, número e comprimento das raízes.

\section{Crescimento das mudas após a aclimatização}

Após a avaliação do enraizamento, as plantas foram transferidas para bandejas de isopor alveoladas (Código 12-72) com células contendo $150 \mathrm{~mL}$ de substrato comercial Plantmax ${ }^{\circledR}$ (Eucatex, São Paulo, BR). As bandejas foram mantidas por 45 dias em casa de vegetação com temperatura de $25 \pm 4^{\circ} \mathrm{C}$. A irrigação foi realizada por aspersão, sendo que a quantidade de água foi adicionada em função das perdas provocadas por evapotranspiração, medida em minitanque Classe A.

Ao final desse período, as plantas foram avaliadas quanto ao percentual de sobrevivência, número, comprimento $(\mathrm{cm})$ e peso da matéria seca das raízes (mg.planta ${ }^{-1}$ ), bem como a altura de plantas $(\mathrm{cm})$, número de folhas e peso da matéria seca da parte aérea (mg.planta $\left.{ }^{-1}\right)$.

Para os dois experimentos, o delineamento experimental utilizado foi o inteiramente casualizado, com 4 repetições, com 11 miniestacas por repetição. Os resultados foram submetidos à análise de variância e regressão polinomial, sendo que os dados de percentagem foram transformados em arc.sen $\sqrt{x} / 100$, conforme Sokal e Rohlf (1995). Para a comparação de médias, foi utilizado o teste de Duncan, a 5\% de probabilidade.

\section{RESULTADOS E DISCUSSÃO}

\section{Enraizamento e aclimatização}

As maiores percentagens de enraizamento (82 e $84 \%$ ) foram observadas nas miniestacas tratadas com 500 e $1000 \mathrm{mg} . \mathrm{L}-$ ${ }^{1}$ de AIB, respectivamente (Tabela 1). O menor percentual de enraizamento (30\%) foi obtido com 1500 mg.L.-1 de AIB. As miniestacas que não receberam $\mathrm{AIB}$, apresentaram enraizamento de $64 \%$, porém significativamente inferior aos observados com AIB 500 ou $1000 \mathrm{mg} . \mathrm{L}^{-1}$. As miniestacas-controle produziram em média 3,5 raízes, valores esses inferiores àqueles obtidos nas miniestacas que receberam AIB. Nos tratamentos com 500; 1000 e $1500 \mathrm{mg} . \mathrm{L}^{-1}$ de AIB, o número de raízes emitidas variou de 6 a 8 , não diferindo estatisticamente entre si. O comprimento das raízes variou de 3,5 a $4,7 \mathrm{~cm}$, sem haver, no entanto, diferenças significativas entre as concentrações de AIB utilizadas.

As altas percentagens de enraizamento ex vitro, obtidas neste trabalho, evidenciam que a concentração de AIB recomendada para o enraizamento deste porta-enxerto está entre 500 e $1000 \mathrm{mg} \cdot \mathrm{L}^{-1}$. Concentrações superiores a $1000 \mathrm{mg} \cdot \mathrm{L}^{-1}$ parecem inibir a percentagem de enraizamento, indicando um possível efeito de fitotoxidez, como foi verificado por Nachtigal (1994). Os resultados obtidos foram superiores aos de James e Thurnbon (1981), que obtiveram $45 \%$ de enraizamento deste porta-enxerto, quando utilizaram fluroglucinol no meio de cultura. Possivelmente, as condições de indução in vitro, utilizadas por estes autores, dificultaram a absorção da auxina, como constatado por Harbage et al. (1998). Além disto, a 
intensidade luminosa da câmara de crescimento pode ter contribuído para inativar parte da auxina contida no meio gelatinoso utilizado por James e Thurnbon (1981). A ausência de luz na base da miniestaca também deve ter favorecido a indução e o crescimento das raízes, pois Khosh-khui e Sink (1982) obtiveram aumento no enraizamento de roseiras quando submeteram a base das estacas a ausência de luz. Da mesma forma, para pereira (Wang, 1991) e macieira (Fortes e Leite, 1993; Zanol, 1996), foi evidenciado que a ausência de luz favoreceu a indução de raízes na base das estacas. Além da ausência de luz, a maior porosidade e aeração dos substratos utilizados podem ter favorecido a indução, a diferenciação e o crescimento de raízes, como foi observado por Jay-Allemand et al. (1992), trabalhando com indução ao enraizamento de miniestacas de Juglans regia.

No presente trabalho, o AIB em $1000 \mathrm{mg} \cdot \mathrm{L}^{-1}$ não aumentou a percentagem de enraizamento em relação a $500 \mathrm{mg} . \mathrm{L}$ 1, enquanto, acima de $1000 \mathrm{mg} . \mathrm{L}^{-1}$, esta foi reduzida a $30 \%$ (Tabela 1). Estes resultados podem estar relacionados com os teores endógenos de auxinas que foram produzidas por gemas e folhas jovens, como sugerem Hartmann et al. (1997), pois mesmo sem aplicação de AIB na base das miniestacas, as percentagens de enraizamento do 'M.9' foram de $64 \%$, superiores aos obtidos por James e Thurnbon (1981). As condições experimentais podem ter determinado o padrão de divisão celular e do crescimento das raízes independentemente da concentração de AIB aplicada, pois as plantas não apresentaram diferenças no comprimento das raízes 30 dias após a indução. Concentrações de $1500 \mathrm{mg} . \mathrm{L}^{-1}$ de AIB podem ter determinado um efeito fitotóxico no tecido da base das miniestacas, diminuindo drasticamente a percentagem de enraizamento (Tabela 1) e aumentando a mortalidade das plantas (Tabela 2).

A exposição das miniestacas às concentrações de $500 \mathrm{e}$ $1000 \mathrm{mg} . \mathrm{L}^{-1}$ de AIB por 10 segundos foi suficiente para a indução de primórdios radiculares e crescimento das raízes sem a formação de calos na base das miniestacas. Estes resultados sugerem que a desdiferenciação e a indução à divisão celular para a formação de um maior número de primórdios radiculares são dependentes da aplicação exógena desta auxina. Períodos maiores de exposição a concentrações elevadas de auxina podem ocasionar aumento da oxidação (James e Thurbon, 1981) e da atividade da peroxidase, reduzindo as concentrações endógenas de ácido indolilacético (Harbage et al., 1998). Isso pode explicar, em parte, a redução no enraizamento das miniestacas que receberam 1500 mg.L. ${ }^{-1}$ de AIB. Os resultados obtidos com o tempo de exposição ao AIB, por 10 segundos, parecem confirmar os resultados de Jarvis et al. (1983) que observaram um aumento na síntese de RNA, no período de 20 horas após a aplicação de auxina exógena, o que corresponde às primeiras divisões celulares. Desta forma, não são necessários longos períodos de exposição ao AIB, como foi utilizado por James e Thurbon (1981), e Harbage et al. (1998).

Os valores do comprimento das raízes formadas não diferiram estatisticamente entre si em função das concentrações de AIB utilizadas, possivelmente porque a auxina aplicada, atua mais sobre a indução ao enraizamento do que sobre o crescimento das raízes. Possivelmente, o crescimento depende de condições físicas e químicas do substrato utilizado e das substâncias de reserva que a planta utiliza para a divisão e elongação celular das raízes.

\section{Crescimento após a aclimatização}

Após 45 dias da repicagem das plantas enraizadas e aclimatizadas para as bandejas alveoladas contendo $150 \mathrm{ml}$ de substrato Plantmax ${ }^{\circledR}$, a sobrevivência das plantas variou de 70 a $95 \%$ (Tabela 2). Os outros parâmetros não foram influenciados pela concentração de AIB utilizada no enraizamento. Para este período de crescimento em casa de vegetação, o comprimento das raízes variou de 11,3 a 12,5 cm, mostrando grande uniformidade apesar das diferentes concentrações de auxina utilizadas na fase de indução. Este resultado pode indicar que este é o padrão de crescimento das raízes do porta-enxerto M.9 enraizado e aclimatizado segundo a metodologia utilizada neste trabalho. A mesma tendência foi observada na altura das plantas e no número de folhas emitidas após 45 dias de crescimento em casa de vegetação. Para este período de cultivo, não houve diferenças significativas em função das concentrações de AIB utilizadas na fase de indução ao enraizamento.

Com relação à matéria seca produzida pelas raízes e parte aérea das plantas, as curvas de regressão mostram um comportamento quadrático, atingindo os maiores valores quando as miniestacas receberam concentrações entre 500 e $1000 \mathrm{mg} . \mathrm{L}^{-}$ ${ }^{1}$ de AIB (Figura 1). A maior produção de matéria seca coincidiu com os tratamentos que apresentaram as maiores percentagens de enraizamento. No entanto, considerando os melhores resultados de enraizamento ( $82 \%)$ e a maior sobrevivência das plantas aos 45 dias após o transplante para a casa de vegetação (95\%), a concentração de $500 \mathrm{mg} . \mathrm{L}^{-1}$ foi a mais efetiva para este porta-enxerto.

Os dados obtidos mostram que a indução ao enraizamento realizado ex vitro, concomitante com a fase de aclimatização, pode ser favorável à produção do porta-enxerto M.9. A principal vantagem deste processo é a superação das limitações impostas pelo enraizamento in vitro, realizado por James e Thurbon (1981), Harbage et al. (1998) e Ferri et al. (1998), pois as raízes produzidas in vitro não são funcionais após sua transferência para casa de vegetação (McClelland et al., 1990). Além disso, segundo Sutter (1988), quando transferidas para a aclimatização, as plantas enraizadas in vitro são submetidas a uma condição de alta transpiração que, associada à alta condutividade hídrica, provoca baixa funcionalidade ou ausência de controle sobre o fechamento dos estômatos. Esta condição provoca altas taxas de mortalidade, o que não foi observado no presente trabalho. $\mathrm{O}$ sistema utilizado neste trabalho permite um grande controle sobre as condições de umidade nos recipientes de aclimatização, diminuindo as perdas de água por evaporação e garantindo, com isto, altas percentagens de enraizamento, aclimatização e sobrevivência deste porta-enxerto após sua transferência para a casa de vegetação.

As plantas enraizadas e aclimatizadas simultaneamente apresentaram grande número de raízes secundárias (Figura 2), o que aumenta a superfície radicular e o volume de substrato explorado. Como conseqüência, aumenta a necessidade de água e nutrientes para o rápido crescimento inicial das plantas, podendo viabilizar o uso desta tecnologia para a produção de porta-enxertos de macieira em escala comercial.

Esta metodologia permite diminuir os custos de produção das mudas, visto que, para a fase de enraizamento, 
TABELA 1 - Enraizamento, número e comprimento de raízes de miniestacas do porta-enxerto de macieira M.9 (Malus pumila), tratadas com AIB e submetidas ao enraizamento ex vitro, em substrato composto por casca de arroz carbonizada e vermiculita média $1: 1(\mathrm{v} / \mathrm{v})$, por um período de 30 dias.

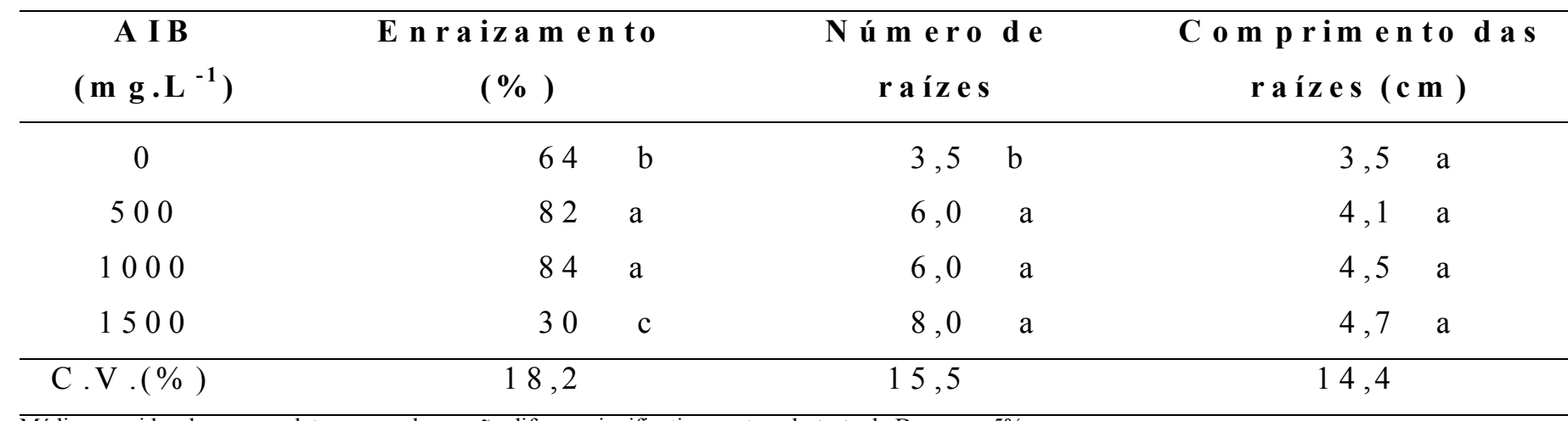

Médias seguidas de mesmas letras nas colunas não diferem significativamente pelo teste de Duncan a 5\%.

TABELA 2 - Sobrevivência, número e comprimento de raízes, altura das miniestacas e número de folhas do porta-enxerto de macieira M.9 (Malus pumila), submetidas ao enraizamento ex vitro, em diferentes concentrações de AIB, aos 45 dias após a repicagem para o substrato Plantmax ${ }^{\circledR}$

\begin{tabular}{|c|c|c|c|c|c|}
\hline $\begin{array}{c}\text { A IB } \\
\left(\mathrm{mg} \cdot \mathrm{L}^{-1}\right)\end{array}$ & $\begin{array}{c}\text { Sobrevivência } \\
\text { das plantas (\%) }\end{array}$ & $\begin{array}{l}\text { Nú mero } \\
\text { de raízes }\end{array}$ & $\begin{array}{c}\text { Comprimento } \\
\text { das raízes } \\
\text { (cm) }\end{array}$ & $\begin{array}{l}\text { A lturadas } \\
\text { m iniestacas } \\
\text { (c m) }\end{array}$ & $\begin{array}{l}\text { Nú m ero } \\
\text { de folhas }\end{array}$ \\
\hline 0 & $85 \quad b$ & $10 \mathrm{a}$ & $12,0 \mathrm{a}$ & $5,3 \mathrm{a}$ & $7,0 \mathrm{a}$ \\
\hline 500 & $95 \mathrm{a}$ & $11 \mathrm{a}$ & $12,5 \mathrm{a}$ & $6,3 \mathrm{a}$ & $8,0 \mathrm{a}$ \\
\hline 1000 & $70 \quad \mathrm{c}$ & $16 \mathrm{a}$ & $11,6 \mathrm{a}$ & 6,9 a & $7,0 \mathrm{a}$ \\
\hline 1500 & $73 \mathrm{c}$ & $20 \mathrm{a}$ & $11,3 \mathrm{a}$ & $6,9 \mathrm{a}$ & 8,0 a \\
\hline C.V.(\%) & 14,3 & 21,5 & 12,1 & 17,3 & 12,2 \\
\hline
\end{tabular}

Médias seguidas de mesmas letras nas colunas não diferem significativamente pelo teste de Duncan a 5\%.

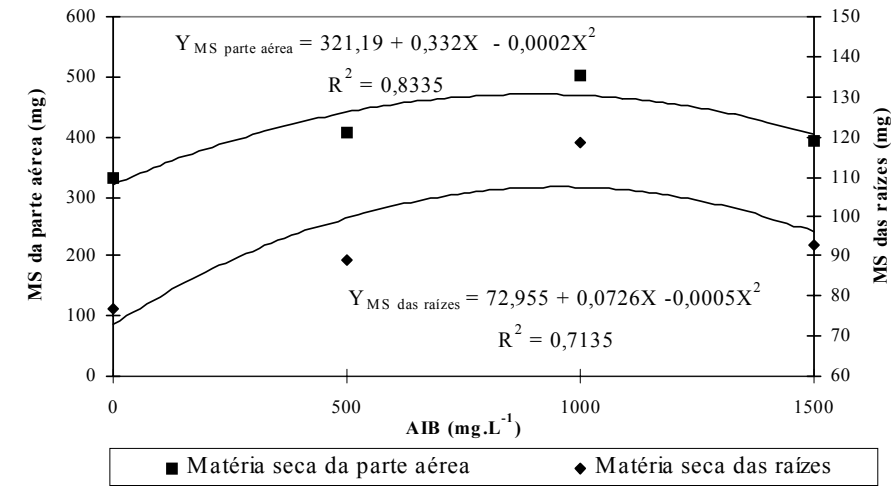

FIGURA 1 - Produção de matéria seca (MS) da parte aérea e das raízes de plantas micropropagadas do portaenxerto de macieira M.9 (Malus pumila), aos 45 dias após a repicagem para substrato Plantmax ${ }^{\circledR}$, em função de diferentes concentrações de AIB utilizadas para o enraizamento ex vitro.

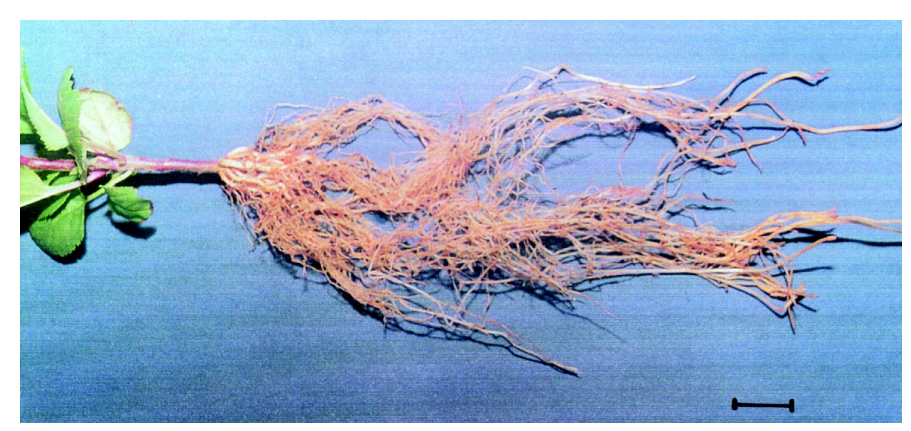

FIGURA 2 - Arquitetura do sistema radicular de miniestacas do porta-enxerto de macieira M.9 (Malus pumila), 30 dias após a indução ao enraizamento ex vitro, e aclimatização em substrato composto por vermiculita média e casca de arroz carbonizada $1: 1(\mathrm{v} / \mathrm{v})$. Barra $=0,5 \mathrm{~cm}$. 
não é necessário utilizar meios de cultura e salas de crescimento assépticas, mão-de-obra especializada para repicagens em capela de fluxo laminar, além de outros custos fixos de um laboratório de cultura de tecidos. Com enraizamento ex vitro, é possível diminuir em, no mínimo, $50 \%$ os custos finais de produção in vitro de uma planta deste porta-enxerto.

\section{CONCLUSÕES}

Nas condições em que os experimentos foram realizados, pode-se concluir que:

1 - As maiores percentagens de enraizamento ex vitro para o porta-enxerto de macieira M.9 são obtidas com 500 e 1000 mg.L${ }^{1}$ de AIB.

2 - A concentração de $500 \mathrm{mg} . \mathrm{L}^{-1}$ de AIB é a mais efetiva para o enraizamento e sobrevivência das plantas, aos 45 dias após o transplante em casa de vegetação.

\section{REFERÊNCIAS BIBLIOGRÁFICAS}

ÁLVAREZ, R.; NISSE, S.J.; SUTTER, E. R. Relationship between indole-3acetic acid levels in apple (Malus pumila Mill) rootstocks cultured in vitro and adventitious root formation in presence of indole-3-butyric acid. Plant Physiology, Minneapolis, v.89, p.439-443, 1989.

BLAKESLEY D.; WESON, G.D.; HALL, J.F. The role of endogenous auxin in root initiation. Plant Growth Regulation, Dordresh, v.10, p.341-353, 1991.

COLLET, G. F.; LÊ, C.L. Role of auxin, during in vitro rhizogenesis of rose and apple trees. Acta Horticulturae, Wageningen, n.212, p. 273-280, 1987.

DE KLERK, G.J.; KEPPEL, M.; BRUGGE, J.T.; MEEKES. H. Timing of the phases in adventitious root formation in apple microcuttings. Journal of Experimental Botany, Oxford, v.46, n.289, p. 965-972, 1995.

DE KLERK,G.J.; BRUGGE, J.T.; MARINOVA, S. Effectiveness of indoleacetic acid, indolebutyric acid and naphthalenacetic acid during adventitious root formation in vitro in Malus 'Jork 9'. Plant Cell, Tissue and Organ Culture, Amsterdam, v.49, p.3944, 1997.

DEBERGH, P.C.; MAENE, L.J. A scheme for commercial propagation for ornamental plants by tissue culture. Scientia Horticulturae, Amsterdam, v.14, p.35-345, 1981.

DÍAZ-PÉREZ, J.C.; SUTTER; E.G.; SHACKEL, K.A. Acclimatization and subsequent gas-exchange, water relations, survival and growth of microcultured apple plantlets after transplanting them in soil. Physiologia Plantarum, Copenhagen, v.95, p. 225-232, 1995.

FERRI, V.C.; CENTELLAS, A. Q.; HELBIG, V.E.; FORTES, G.R.L. Uso de ágar, amido e ácido indolbutírico no enraizamento in vitro do porta-enxerto de macieira MM 111. Ciência Rural, Santa Maria, v.28, n.4, p. 561-565, 1998.

FORTES, G.R.L.; LEITE, G.L. Enraizamento in vitro de brotações adventícias de macieira (Malus domestica Borkh) 1. Pré-condicionamento ao escuro e presença de floroglucinol. Revista Brasileira de Fisiologia Vegetal, Piracicaba, v. 5, n.1, p.101, 1993.

HAISSIG, B. E.; DAVIS, T. D.; RIEMENSCHNEIDER, D. E. Researching the controls of adventitious rooting. Physiologia Plantarum, Copenhagen, v.84, p.310-317, 1992.

HARBAGE, J. F.; STIMART, D.P.; AUER, C. $p H$ affects ${ }^{1} \mathrm{H}-$ indol-3-butyric acid uptake but not metabolism during the initiation phase of adventitious root induction in apple microcuttings. Journal of the American Society for Horticultural Science, Washington, n.123, v.1, p. 6-10, 1998.

HARBAGE, J. F; STIMART, D.P. Effect of $\mathrm{pH}$ and ${ }^{1} \mathrm{H}$-indol-3 butyric acid (IBA) on rooting of apple microcuttings. Journal of the American Society for Horticultural Science, Alexandria, v. 121, n. 6, p. 1049-1053, 1996.

HARTMANN, H.T.; KESTER, D.E.; DAVIES Jr., F.T.; GENEVE, R.L. Plant propagation: principles and practices. 6. ed. Singapore: Prentice-Hall, 1997. 770p.

ICEPA 2000 http://www.icepa.rct-sc.br/produtos/tabprodução/ comparativos.htm

JAMES, D.J.; THURNBON, I.J. Phenolic compounds and other factors controlling rhyzogenesis in the apple rootstocks M.9 e M.26. Zeitschrift Pflanzenphysil, Villengang, Germany, v.105, p. 11-20, 1981.

JARVIS, B.C.; SHANNON, P.R.M.; YASMIN, S. Influence of IBA and cordycepin on rooting and RNA synthesis in stem cuttings of Phaseolus aureus Roxb. Plant Cell Physiology, Kyoto, v.24, p. 139-146, 1983.

JAY-ALLEMAND, C.; PENG, S.; CAPELLI, P. E CORNU, D. Micropropagation of hybrid walnut trees. Some factors involved in rooting. Acta Horticulturae, Wageningen, n. 311, p.117-124, 1992.

KHOSH-KHUI, M.; SINK, K.C. Rooting-enhancement of Rosa hybrida for tissue culture propagation. Scientia Horticulturae, Amsterdam, n.17, p.371-376, 1982.

MARKS, T. R. Rhododendron cuttings. II. Factors affecting rooting following micropropagation. Journal of Horticultural Science, Washington, v.66, n.1, p.113-118, 1991.

McCLELLAND, M.T.; SMITH, M.A.L.; CAROTHERS, Z.B. The effects of in vitro and ex vitro root initiation on subsequent microcutting root quality in three woody plants. Plant Cell Tissue and Organ Culture, Dordrecht, v. 23, p. 115-123, 1990.

MURASHIGUE, T. E.; SKOOG, F. A revised medium for rapid growth and bioassay with tobacco tissue cultures. Physiologia 
Plantarum, Copenhagen, v.15, p.473-479, 1962.

NACHTIGAL, J.C. Propagação de araçazeiro (Psidium cattleyanum Sabine) através de estacas semilenhosas. Pelotas, RS, 1994. 66p. Dissertação (Mestrado em Fruticultura de Clima Temperado) - Faculdade de Agronomia Eliseu Maciel, Universidade Federal de Pelotas.

PEDROTTI, E.L. Etude de l'organogenèse in vitro à partir de racines, de feullies et d'embryons zygotiques de merisier (Prunus avium L.), 1993. 167p. Tése (Doutorado em fisiologia vegetal)- Université d'Orléans, Orléans, 1993.

SOKAL, R.R.; ROHLF, F.J. Biometry, 3. ed. San Francisco: Freeman and Company, 1995. 776p.

SUTTER, E. Stomatal and cuticular water loss from apple, cherry and sweetgum plants after removal from in vitro culture. Journal of American Society for Horticultural Science, Washington, v.113, n.2, p.234-238, 1988.

VANTELGEN, H.J.; VANMIL, A. ; KUNNEMAN, B. Effect of propagation and rooting condition on acclimatization of micropropagated plants. Acta Botanica Neerlandica, Amsterdan, v.41, n.4, p.453-459, 1992.

WANG, Q. Factors affecting rooting of microcuttings of the pear rootstock BP10030. Scientia Horticulturae, Amsterdam, v. 45, p. 209-213, 1991.

ZANOL, G.C. Enraizamento in vitro do porta-enxerto MARUBAKAIDO (Malus prunifolia) influenciado pela exposição de períodos de escuro, concentrações de ácido indolbutírico e floroglucinol. 1996. 92p. Dissertação (Mestrado em Fruticultura de Clima Temperado) - Faculdade de Agronomia Eliseu Maciel, Universidade Federal de Pelotas - RS, Pelotas, 1996. 